\title{
Concreto com borracha de recauchutagem de pneu para uso em pavimentação de baixo tráfego
}

\author{
Concrete with tire rubber for use \\ in low traffic paving
}

\footnotetext{
${ }^{1}$ Instituto Federal de Ciência e Tecnologia do Pará - Campos Belém, Avenida Almirante Barroso, 1155, CEP: 66093020. - Marco, Belém, Pará, Brasil.

e-mail: eng.luzilene@gmail.com, ribamar.mouta@gmail.com,mbcosta05@gmail.com, laercio.gouvea@gmail.com
}

\section{RESUMO}

O aumento da demanda por veículos acarreta maior produção de novos pneus. No entanto, após o término de sua vida útil, eles se tornam um passivo ambiental de difícil descarte adequado, tanto pela demora em se decompor quanto por seu grande volume. Sua disposição inadequada causa grandes danos ao meio ambiente e favorece a proliferação de vetores que causam doenças ao ser humano. Com o intuito de contribuir com a logística reversa dos pneus inservíveis, o presente trabalho teve como objetivo, produzir um concreto com inserção de resíduo de borracha de recauchutagem de pneu em teores de $6 \%$ e $9 \%$ em massa, para fabricação de placas de pavimentação intertravada de baixo tráfego. O procedimento experimental da pesquisa consistiu na avaliação do comportamento mecânico, bem como, absorção de água, índice de vazios e massa específica do concreto. Também foram feitas análises macroscópicas e microscópicas com a utilização de estereoscópio e Microscópio Eletrônico de Varredura (MEV), respectivamente. Por fim, foi realizada uma avaliação quantitativa do benefício ambiental gerado pelo uso dos resíduos e uma análise de custos para produção de concreto com borracha. Os resultados demonstraram que adição de borracha promove uma pequena redução na resistência axial do concreto da ordem de 15,24\% e 17,27\% para as composições com teores de 6\% e 9\%, respectivamente. No entanto, todos os traços produzidos atingiram valores superiores aos $35 \mathrm{MPa}$ estabelecidos pela ABNT: NBR 9781/2013, sendo assim indicados para utilização em vias de baixo tráfego. O concreto com borracha ainda apresentou vantagens, tais como, redução da massa específica e diminuição dos custos de produção em $4 \%$. As análises apontam para a viabilidade técnica, econômica e ambiental desta tecnologia, que contribui para gestão dos pneumáticos inservíveis e confecção de peças de pavimentação de qualidade satisfatória de acordo com os padrões técnicos estabelecidos.

Palavras-chave: Concreto com borracha, Propriedades físicas e mecânicas, Análise de custos.

\section{ABSTRACT}

The ever-growing demand for new cars implies that more tires are fabricated each year. Nevertheless, after the end of their lifespan, they become an environmental passive of difficult final disposition, both because of their big volume and because of their lengthy decomposition. Discarding them inadequately causes important damages to the environment and favors the proliferation of vectors of human diseases. In order to contribute to the reversal logistics of unserviceable tires, this work aims at, to create a concrete with the insertion of tire retreading rubber residue in proportions of $6 \%$ and $9 \%$ in weight, to be used in the manufacturing of interlocked blocks for low-traffic pavements. The experimental method consisted of analyzing the mechanical behavior and absorption of water, gradation and specific weight. Macroscopic and microscopic analysis with the utilization of stereoscope and Scanning Electron Macroscope (SEM), respectively, were also conducted. Finally, a quantitative evaluation of the environmental benefits of the use of the residue was made, as well as an analysis of the costs of manufacturing a concrete with rubber. The results demonstrate

that the addition of rubber allows for a minor reduction of the concrete's strength by $15.24 \%$ and $17.27 \%$ for $6 \mathrm{wt} \%$ and $9 \mathrm{wt} \%$ of added rubber, respectively. However, all the mixes produced exceeded the level of 35 MPa required in Brazilian regulations (ABNT: NBR 9781/2013), thus fit for the use in low-traffic roads. The concrete with rubber also offered advantages such as reduction of specific weight and $4 \%$ lower production 
costs. From the analysis, the technical, economic and environmental viability of this alternative is established, being it useful for the for the management of unserviceable of pneumatics and for the manufacturing of paving blocks of satisfactory quality according to the most accepted technical standards.

Keywords: Rubber concrete, Mechanic and physic properties, Costs analysis.

\section{INTRODUÇÃO}

A criação dos pneus foi tão relevante para o aprimoramento e intensificação da circulação de bens e pessoas, que até hoje grande parte dos sistemas de transporte utiliza-os como insumo básico. Contudo, após o término de sua vida útil, devido à massificação de sua utilização, eles impõem um importante desafio de logística reversa, constituindo um passivo ambiental de difícil disposição final, tanto por sua decomposição demorada quanto por seu grande volume. Além da poluição visual das pilhas de pneus dispostas a céu aberto e dos riscos de insegurança hídrica associados àquelas que se formam no leito de rios, substâncias tóxicas são liberadas no ar, criadouros para vetores de doenças surgem, e incêndios de difícil controle podem se alastrar rapidamente (PELISSER e BERNADIN) [1].

Segundo a Associação Nacional da Indústria de Pneumáticos - ANIP [2], no ano de 2016 foram produzidos 67.870,35 novos pneus no Brasil, e em torno de 35 milhões foram descartados. No primeiro quadrimestre de 2017, foi registrada uma alta no índice de produção, em torno de 1,8\%, impulsionada principalmente por pneus agrícolas $(33,6 \%)$ e caminhonetas $(12,2 \%)$.

A Resolução $n^{\circ} 258$ do Conselho Nacional do Meio Ambiente - CONAMA [3], determinou que os fabricantes são os responsáveis por dar um destino final ao montante descartado. Para cada novo pneu introduzido ao mercado, deve ser dada uma destinação adequada a um inservível. De acordo com a Revista Pesquisa FAPESP [4], desde que esta lei entrou em vigor já foram criados mais de 1.008 pontos de coleta, sendo que no ano de 2014, cerca de 90 milhões de pneus foram coletados para terem uma destinação ecologicamente adequada.

Todo pneu em algum momento se transformará em um resíduo potencialmente danoso à saúde pública e ao meio ambiente. Uma solução para sua destinação final deverá ser adotada a fim de lidar com os riscos apresentados por este produto ao fim de sua vida útil (BERTOLLO, et. al.,) [5].

Uma das formas de reaproveitamento deste material é a reciclagem. Segundo OLIVEIRA E CASTRO [6], existem dezenas de formas de reciclagem de pneus. Os processos que não alteram as propriedades químicas do material são denominados reciclagens mecânicas, como é o caso da reforma e da recuperação. Já os processos que alteram as composições químicas do pneu são chamados de reciclagem química ou industrial.

A recauchutagem de pneus contribui para reduzir o volume desse passivo ambiental. No entanto, as bandas de rodagem substituídas vêm a constituir resíduo que demanda seu próprio descarte adequado. Uma das possibilidades que vêm sendo estudadas para o reaproveitamento deste material é o seu emprego em misturas cimentícias (PELISSER e BERNADIN) [1].

O concreto é um material amplamente utilizado na construção civil, resultante da mistura, em quantidades racionais, de aglomerante (cimento), agregados (pedra e areia) e água. Logo após a mistura, o concreto deve possuir plasticidade suficiente para as operações de manuseio, transporte e lançamento em fôrmas, adquirindo coesão e resistência com o passar do tempo, devido a reações entre o aglomerante e a água (GRANZOTTO) [7].

No intuito de melhorar algumas propriedades desse compósito bem como reduzir o passivo ambiental causado pela deposição inadequada de pneumáticos na natureza, pesquisadores vêm desenvolvendo estudos sobre a viabilidade da inserção de resíduos de recauchutagem de pneus na fabricação de concreto. Até então, a maioria dos estudos estavam voltados à incorporação da borracha ao asfalto para fabricação de asfalto borracha. No entanto, pesquisas recentes têm indicado o potencial do uso deste produto como agregado do concreto, um dos materiais mais consumidos no mundo, com importância primária na indústria de construção civil (PELISSER e BERNADIN) [1].

FIORITI et al., [8] substituiram parcialmente os agregados por resíduo de recauchutagem, em frações volumétricas de $(8 \%, 10 \%$ e $12 \%)$, para pavimentação intertravada com blocos de concreto, e, apesar de queda na resistência à compressão do compósito, a absorção e a tenacidade à fratura foram melhoradas, demonstrando que o pavimento é indicado para locais de baixo trafégo. 
LINTZ e BARBOSA [9] avaliaram as propriedades mecânicas de concretos para pisos intertravados, com incorporações crescentes de resíduo de borracha vulcanizada, em substituição parcial aos agregados naturais de $(2,5 \%, 5 \%, 7,5 \%$ e $10 \%)$, demonstrando a viabilidade técnica na razão de até 2,5\%.

SILVA [10] avaliou a borracha de recauchutagem, em substituição parcial do agregado miúdo natural em porcentagens de $(10 \%, 20 \%, 30 \%, 40 \%$ e $50 \%)$ para a produção de pisos táteis intertravados de concreto, e, apesar da redução das resistências mecânicas, os traços atingiram ótimos valores de resistência à compressão e resistência à tração na flexão e melhor resistência à abrasão.

ALTOÉ [11] demonstrou que o resíduo de pneu é substituto viável ao agregado miúdo em (2\%, 5\% e $7 \%$ ) nos pavers sujeitos a solicitações leves, apesar de redução na resistência à compressão e um aumento na absorção de água.

Substituindo o agregado miúdo, o resíduo de borracha proporciona uma redução de 10 a $30 \%$ da massa específica do concreto seco (KROTH) [12].

PELISSER e BERNADIN [1] obtiveram bons resultados para o concreto com inserção de borracha e sílica ativa, com perda na resistência à compressão de apenas 14\%, e resistência média final de $48 \mathrm{MPa}$, podendo ser empregado em pavimentação acordo com as normas vigentes.

O concreto com borracha possui maior ductilidade pelas taxas de deformação mais elevadas antes do ponto de ruptura, principalmente quando partículas de borracha maiores que $4,75 \mathrm{~mm}$. Também há melhora nas propriedades de resistência à abrasão e a cavitação, sendo útil em estruturas submetidas a impacto, por absorver grande quantidade de energia, com ruptura frágil em vez de dúctil, e mais durabilidade que o convencional (GRANZOTTO) [7].

Com base na revisão da literatura, verificou-se que o concreto com resíduo de borracha pode ter atributos como: maior leveza, devido à baixa densidade da borracha, maior isolamento acústico e térmico, melhor resistência à tenacidade a fratura e possível redução de custo do produto final, dado o incremento do volume proporcionado pela borracha. Estes são atributos interessantes nas diversas aplicações do concreto. Por isso, o presente trabalho teve por objetivo produzir um concreto com inserção de resíduo de borracha de recauchutagem de pneu, avaliando sua viabilidade técnica e econômica para o emprego em fabricação de placas de pavimentação intertravada de baixo tráfego.

\section{MATERIAIS E MÉTODOS}

A fase laboratorial deste estudo foi dividida em sete etapas, constando de: caracterização dos materiais (agregados miúdo, agregado graúdo e resíduo de borracha); determinação da dosagem do concreto; confecção e moldagem dos corpos de prova; realização dos ensaios físico-mecânicos; estudo da morfologia da fratura do compósito; análise quantitativa do benefício ambiental gerado pelo uso do resíduo de borracha em concreto, e por fim, avaliação econômica da produção do compósito modificado.

\subsection{Materiais Utilizados}

Para a confecção do concreto utilizou-se o cimento CP II-F-40, areia natural, seixo de origem quartzosa, água, e resíduo de borracha de pneus, proveniente do processo de recauchutagem de uma fábrica localizada na região metropolitana de Belém-PA. Este resíduo é composto por grânulos de diversas formas e tamanhos, compreendendo desde partículas muito pequenas em formato de pó, até fibras que podem ser muito curtas ou mais alongadas, conforme ilustrado na Figura 1. 


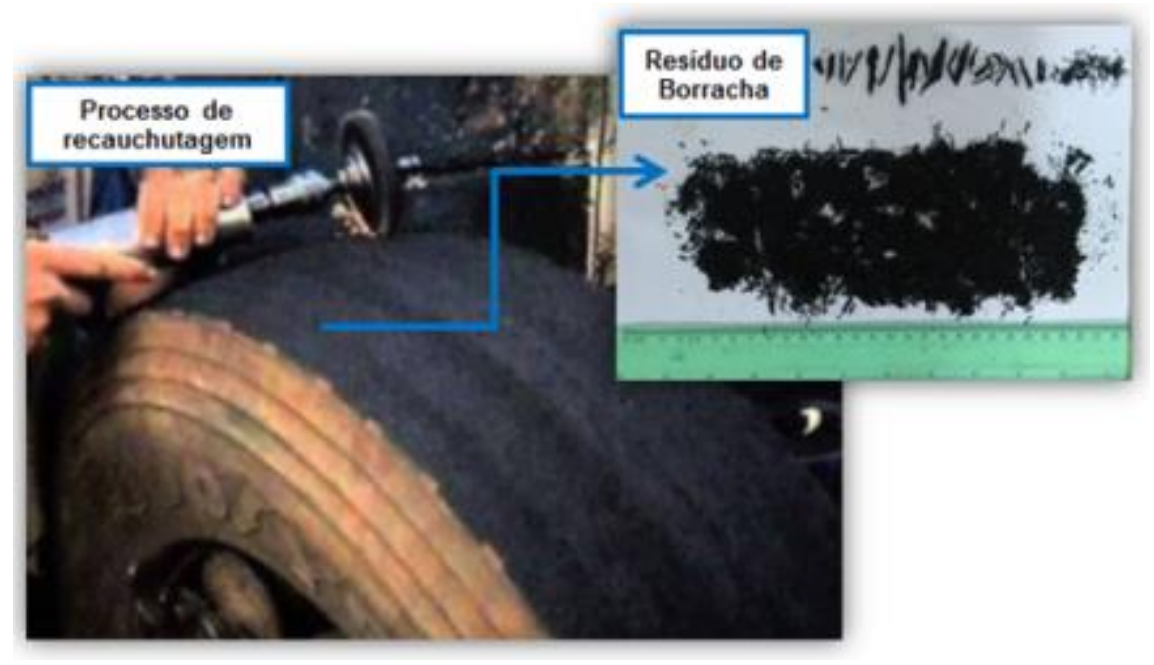

Figura 1: Resíduo de Borracha de Pneu Utilizado

\subsection{Caracterização dos Materiais}

Os componentes do concreto foram submetidos a ensaios para determinação de suas propriedades físicas, conforme as normas vigentes. $\mathrm{O}$ ensaio da composição granulométrica seguiu os procedimentos estabelecidos pela NBR: NM 248[13].

Para a determinação da massa específica da areia seguiu-se os procedimentos adotados pela NBR: NM 52 [14]. A aferição da massa específica do agregado graúdo baseou-se na NBR: NM 53 [15]. Para o resíduo de borracha, devido não existir uma norma específica, utilizou-se a Norma ASTM C 792 [16], com algumas adaptações. Inicialmente, pesou-se duas amostras de $500 \mathrm{Kg}$, cada uma, que foram colocadas em estufa por um período de 4 horas, a uma temperatura de $\left(110^{\circ} \mathrm{C}\right)$. Depois desse intervalo, as amostras foram resfriadas ao ar durante 2 horas e então inseridas em uma proveta contendo $\left(500 \mathrm{dm}^{3}\right)$ de querosene à temperatura de 25 ${ }^{\circ} \mathrm{C}$. Após a inserção do resíduo, foi feita a agitação do frasco para eliminação das bolhas de ar e então realizou-se a leitura do nível atingido pelo líquido no gargalo do frasco indicando o volume em $\mathrm{cm}^{3}$ ocupado pelo conjunto (água-agregado). Com esses dados determinou-se a massa específica da borracha.

Utilizou-se o procedimento de ensaio estabelecido pela NBR: NM 45 [17] para determinação da massa unitária dos agregados e do resíduo de borracha.

\subsection{Determinação da Dosagem}

Utilizou-se o método da ABCP (Associação Brasileira de cimento Portland) para determinação da dosagem do concreto. Após a caracterização dos agregados e do resíduo, primeiramente estipulou-se o fck do concreto que seria produzido. Tendo em vista que o objetivo era avaliar a viabilidade de aplicação deste material para confecção de piso intertravado, fixou-se o fck em $35 \mathrm{MPa}$, conforme o que estabelece a ABNT: NBR 9781 [18], e utilizou-se o desvio padrão de (5,5), obtendo-se assim, um fck $=44 \mathrm{MPa}$.

Utilizando-se a curva de Abrams, estabeleceu-se a relação água/cimento em (0,45), chegando assim ao consumo de materiais necessários para a produção de $1 \mathrm{~m}^{3}$ de concreto (sem adição de borracha). A apresentação do traço ficou da seguinte forma: (1: 1,17: 2,74). Foram utilizados três traços, sendo um de referência (sem adição de resíduo), e outros dois com adição de (6\% e $9 \%$ em massa de borracha, em relação ao agregado miúdo).

\subsection{Fabricação do Concreto}

Primeiramente, pesou-se todas as quantidades de materiais necessários para confecção dos traços para então seguir ao procedimento de produção do concreto, nesta ordem: umidificação da betoneira; colocação de todo o agregado graúdo; colocação de metade da areia; inserção de metade da água; mistura na betoneira por 1 
minuto; adição de todo o cimento; adição do restante de areia; inserção da borracha (para o traço de referência - pular essa etapa); homogeneização dos materiais na betoneira por mais 3 minutos, e; mistura do restante de água, rodando a betoneira por mais 2 minutos.

Para verificar a consistência do concreto no estado fresco, retirou-se uma amostra que foi submetida ao ensaio do abatimento pelo tronco de cone (slump test), segundo o que estabelece a NBR: NM 67 [19]. Para cada um dos traços confeccionados obteve-se um slump diferente, sendo eles: $55 \mathrm{~mm}$ (para o concreto de referência); $40 \mathrm{~mm}$ (para adição de $6 \%$ de borracha) e; $35 \mathrm{~mm}$ (para adição de $9 \%$ de borracha). Após a moldagem, os corpos de prova foram postos em um tanque para cura úmida até as datas de serem ensaiados.

\subsection{Ensaios Físicos e Mecânicos}

\subsubsection{Ensaio de Resistência à Compressão Axial}

O ensaio de compressão axial simples foi realizado segundo as recomendações da ABNT: NBR 5739 [20], que prescreve uma metodologia, na qual devem ser ensaiados à compressão os corpos de prova cilíndricos de concreto, moldados conforme a ABNT NBR 5738 [21]. Utilizou-se 4 corpos de prova cilíndricos para cada traço, que foram ensaiados aos 7, 14 e 28 dias de cura. Após o procedimento, realizou-se a determinação da resistência à compressão axial simples, dividindo-se o valor da força aplicada pela área do corpo de prova rompido, conforme a (Equação 1) a seguir, retirada da ABNT: NBR 5739 [20].

$$
f c=\frac{4 F}{\pi d^{2}}
$$

Onde:

$\mathrm{f}_{\mathrm{c}}$ : resistência à compressão, em Megapascal;

F: força máxima alcançada, em Newtons;

d: diâmetro do corpo-de-prova, em milímetros.

\subsubsection{Massa específica, Absorção de Água e Índice de Vazios}

Para este ensaio foram utilizados 3 corpos de prova para cada composição estudada. Seguiu-se os procedimentos descritos na ABNT: NBR 9778 [22]. Primeiramente retirou-se os corpos de prova da cura após 28 dias e determinou-se a massa da amostra ao ar, em seguida foram colocadas na estufa a temperatura de $\left(105{ }^{\circ} \mathrm{C}\right)$, e determinou-se a massa após intervalos de $24 \mathrm{~h}$, $48 \mathrm{~h}$ e $72 \mathrm{~h}$ de permanência na estufa. Posteriormente, procedeu-se à imersão da amostra em água à temperatura $\left(23{ }^{\circ} \mathrm{C}\right)$, de maneira gradual, primeiro $1 / 3$ do seu volume nas primeiras 4 horas e $2 / 3$ nas 4 horas seguintes, sendo completamente submerso nas $64 \mathrm{~h}$ restantes. Em cada uma das condições foi registrada a massa do corpo de prova.

\subsection{Análise da Morfologia da Superfície de Fratura}

A Análise da superfície de fratura foi realizada para todos os traços produzidos. Após o rompimento dos corpos de prova, por meio do ensaio de compressão axial. Selecionaram-se amostras de concreto que foram retiradas com o auxílio de um disco de corte. Posteriormente, as amostras foram lavadas em água corrente e colocadas em estufa por um período de 2 horas à temperatura de $55^{\circ} \mathrm{C}$. Após isso, foram feitas as análises macroscópicas em um estereoscópio e microscópicas em um microscópio eletrônico de varredura (MEV). No primeiro caso buscou-se verificar as formas de arrancamento das fibras de borracha, e no segundo procurouse observar a interface entre a borracha e a pasta cimentícia, bem como, seu grau de aderência.

\subsection{Análise Quantitativa do Benefício Ambiental Gerado Pelo uso de Resíduos de Borracha de Pneus em Concreto}

A fim de constatar os benefícios ambientais gerados pelo uso de resíduos de borracha de pneu de recauchutagem em concretos, procurou-se fazer uma análise quantitativa demonstrando o percentual de resíduos que seriam reutilizados para confecção de pisos intertravados, contribuindo desta maneira, para a logística reversa deste material. Para a quantificação dos resíduos gerados em cada processo de recauchutagem utilizou-se informações retiradas do site da Associação Brasileira do Seguimento de Reforma de Pneus. 


\subsection{Análise Quantitativa da Redução de Custos no Concreto com Borracha}

Tendo em vista a importância da avaliação da viabilidade econômica para a produção de concreto com uso de resíduos de recauchutagem de pneus, realizou-se uma análise comparativa entre o compósito tradicional e o modificado, para obtenção do valor de confecção de $\left(1 \mathrm{~m}^{3}\right)$ de cada tipo de concreto. As quantidades individuais dos insumos foram obtidas por meio dos traços que haviam sido confeccionados e os preços de compra de cada um deles foram retirados da tabela de composições do SINAPI (2018) do estado do Pará. Considerou-se custo zero para o resíduo, tendo em vista que este material não necessitou passar por nenhum tratamento prévio para inserção no concreto e é considerado como um passivo ambiental, sendo descartado pelas fontes geradoras. Os valores finais apresentados são referentes apenas ao custo dos materiais para produção do concreto, não levando em consideração transporte e mão de obra.

\section{RESULTADOS E DISCUSSÕES}

\subsection{Características Físicas dos Agregados}

A Tabela 1 apresenta os resultados dos ensaios de determinação de composição granulométrica, massa específica e massa unitária dos agregados. Conforme a classificação da ABNT: NBR 7211 [23], a areia por apresentar um módulo de finura de $(1,80)$ enquadra-se na faixa da Zona Utilizável Inferior. O seixo assemelha-se a brita zero, já que a sua curva granulométrica encontra-se entre os limites superiores e inferiores dos parâmetros desse tipo de agregado. A borracha, por sua vez, extrapola todos os limites para ser considerado como agregado miúdo, sendo, portanto, classificado como agregado graúdo.

Em relação à massa específica e massa unitária. Verifica-se que, a borracha possui baixos valores para essas grandezas em comparação com o seixo e a areia. Os valores obtidos na presente pesquisa estão em consonância com as informações obtidas nas literaturas pesquisadas, onde a massa unitária da borracha varia de 0,27 a $0,50 \mathrm{~g} / \mathrm{cm}^{3}$, enquanto que a massa especifica mais recorrente é de $1,14 \mathrm{~g} / \mathrm{cm}^{3}$.

Tabela 1: Caracterização Física dos Agregados

\begin{tabular}{|c|c|c|c|c|}
\hline Material & $\begin{array}{c}\text { Massa Específica } \\
\left(\mathrm{g} / \mathrm{cm}^{3}\right)\end{array}$ & $\begin{array}{l}\text { Massa unitária } \\
\qquad\left(\mathrm{g} / \mathrm{cm}^{3}\right)\end{array}$ & $\begin{array}{l}\text { Dimensão Máxima } \\
\text { Característica }(\mathbf{m m})\end{array}$ & $\begin{array}{l}\text { Módulo de } \\
\text { Finura }\end{array}$ \\
\hline $\begin{array}{l}\text { Agregado miúdo natural } \\
\text { (areia) }\end{array}$ & 2,63 & 1,69 & 1,18 & 1,80 \\
\hline Agregado graúdo (seixo) & 2,65 & 1,58 & 19,0 & 6,55 \\
\hline Resíduo de borracha & 1,11 & 0,35 & 6,3 & 4,55 \\
\hline
\end{tabular}

\subsection{Resistência à Compressão Axial}

A Figura 2 apresenta os resultados das médias aritméticas dos ensaios de compressão axial simples que foram realizados aos 7, 14 e 28 dias de cura do concreto. Observa-se que a adição de borracha promove a queda gradativa da resistência do concreto, fato este que já era esperado, tendo em vista os resultados verificados nas literaturas existentes sobre o tema $[8,9,11,24,25,26]$. A queda gradativa da resistência à compressão pode ser devido a pouca aderência existente entre a borracha e a matriz cimentícia. No entanto, devido à aplicação final proposta para esse compósito ser a pavimentação de baixo tráfego, o objetivo deste trabalho foi alcançado, pois a menor resistência obtida foi referente ao concreto com adição de $9 \%$ de borracha com 41,6 MPa. Este valor está acima dos $35 \mathrm{MPa}$ estabelecidos pela ABNT: NBR 9781 [18]. 


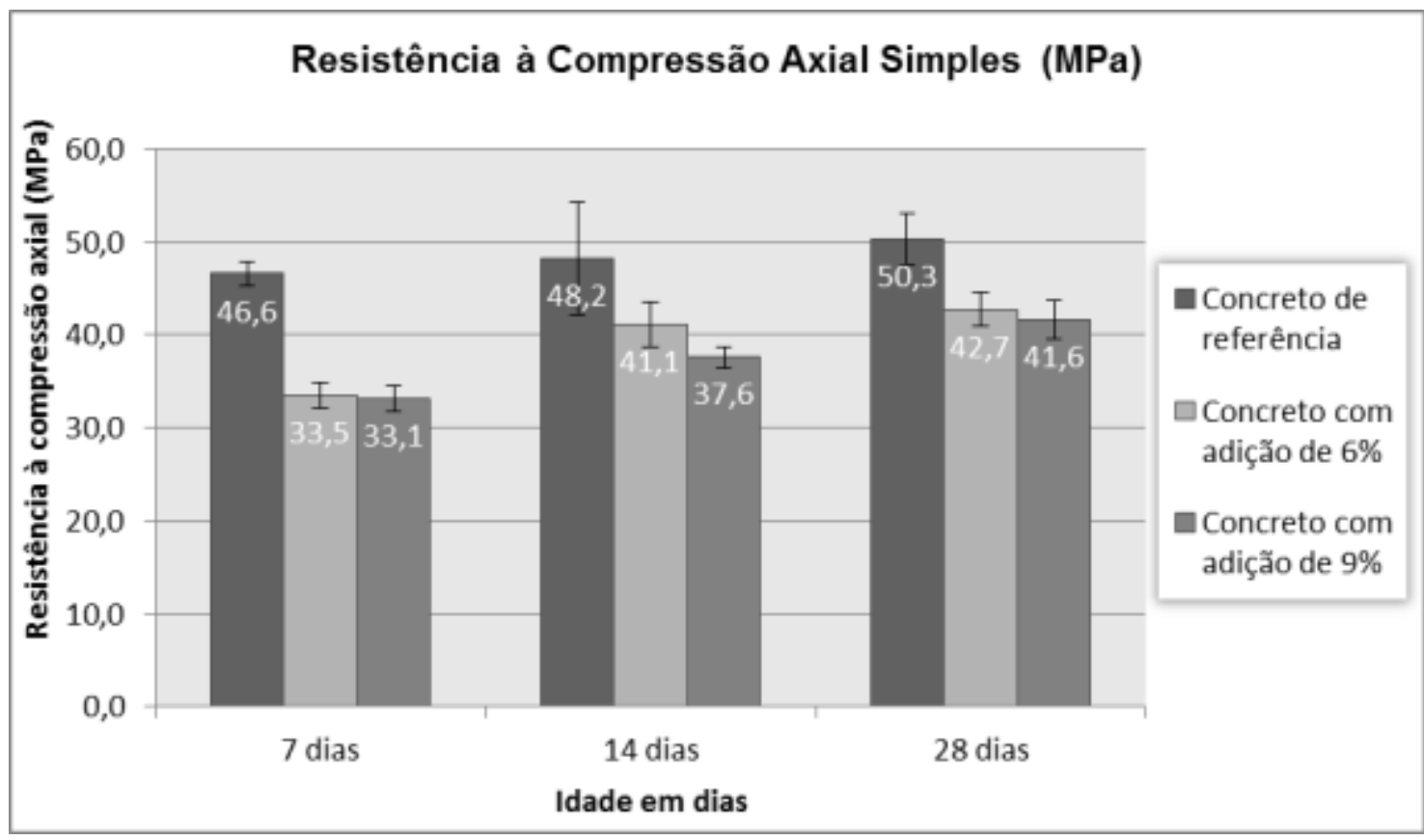

Figura 2: Resistência à Compressão Axial Simples.

A Tabela 2 apresenta a média aritmética dos resultados de compressão axial simples, o desvio padrão, e as porcentagens de perda de resistência do concreto com borracha em relação ao compósito tradicional.

Tabela 2: Resultados dos Ensaios de Compressão Axial Simples

\begin{tabular}{cccccccccc}
\hline & \multicolumn{8}{c}{ Compressão axial (MPa) } \\
\cline { 2 - 9 } Corpos de prova & \multicolumn{7}{c}{ Concreto de Referência } & Concreto com 6\% de Borracha & Concreto com 9\% de Borracha \\
\cline { 2 - 9 } & 7 dias & 14 dias & 28 dias & 7 dias & 14 dias & 28 dias & 7 dias & 14 dias & 28 dias \\
\hline Média & 46,6 & 48,2 & 50,3 & 33,5 & 41,1 & 42,7 & 33,1 & 37,6 & 41,6 \\
\hline \begin{tabular}{c} 
Desvio Padrão \\
\cline { 2 - 9 } $\begin{array}{c}\text { Perda de Resistência } \\
(\%)\end{array}$
\end{tabular} & 1,32 & 6,03 & 2,72 & 1,43 & 2,40 & 1,81 & 1,35 & 1,11 & 2,03 \\
\hline
\end{tabular}

Os resultados dos ensaios de compressão axial simples demonstram que existe uma relação inversamente proporcional entre a quantidade de borracha inserida no concreto e sua queda de resistência. Entre os quatro corpos de prova utilizados para cada ensaio. Ao analisar a queda de resistência do concreto por idade de rompimento, verifica-se que aos 7 dias o concreto com borracha, tanto o de $6 \%$ quanto o de $9 \%$ apresentam uma queda de resistência de aproximadamente $30 \%$ em relação ao concreto convencional, sendo que aos 28 dias essa diferença diminui para 15,14\% e 17,27\% para o compósito com adição de 6 e $9 \%$, respectivamente. Estes resultados se mostram satisfatórios, tendo em vista os trabalhos realizados por outros autores, como ALTOÉ [10] que obteve uma redução de 54,6\% para o concreto com adição de $7 \%$ de borracha e 79,84\% para uma adição de $10 \%$, e FIORITI et al. [7], que observaram uma queda de 18, 13\% de resistência para o concreto com adição de $8 \%$ de resíduo de borracha e 22,46\% para o adicionado com $10 \%$. É valido ressaltar, no entanto, que os trabalhos citados realizaram a substituição em fração parcial em massa de agregado miúdo pelo resíduo de borracha, enquanto que na presente pesquisa foi feita apenas a adição. 


\subsection{Massa Específica, Absorção de Água e Índice de Vazios}

A Figura 3 apresenta os resultados obtidos para as três variáveis analisadas. Observa-se que o concreto com $9 \%$ de adição de borracha apresentou uma menor absorção de água $(0,19 \%)$ em relação ao concreto de referência, demonstrando que este compósito possui um menor número de poros permeáveis. No entanto, não foi observada uma relação diretamente proporcional com o teor de borracha adicionado, tendo em vista que $o$ concreto com 6\% de adição teve um resultado de absorção superior ao concreto de referência de $(10,86 \%)$. Estas discordâncias podem estar relacionadas às diferenças de energia de compactação no processo de adensamento manual.

Os resultados obtidos são semelhantes aos encontrados por FIORITI et al., [7], que ao proporem a substituição parcial da areia por resíduo de borracha constataram que absorção de água não é afetada de maneira significativa.

Segundo a ABNT: NBR 9781 [18], a absorção de água, expressa em porcentagem, representa a porosidade do concreto, devido à penetração de água em seus poros permeáveis, em relação à sua massa em estado seco. Para concretos aplicados em pavimentação, esta norma estabelece que os valores médios de absorção não devem ser superiores a $6 \%$ e os individuais não devem ultrapassar $7 \%$. Dessa forma, os três traços analisados neste trabalho estariam em consonância com tais exigências.

Em relação ao índice de vazios, os resultados são praticamente iguais aos da absorção, dada a relação direta entre estas duas variáveis. No que diz respeito à massa especifica, foi observado que o concreto com adição de $6 \%$ teve uma redução de 3,04\% em relação ao concreto de referência, enquanto que compósito com $9 \%$ de borracha reduziu $1,74 \%$.

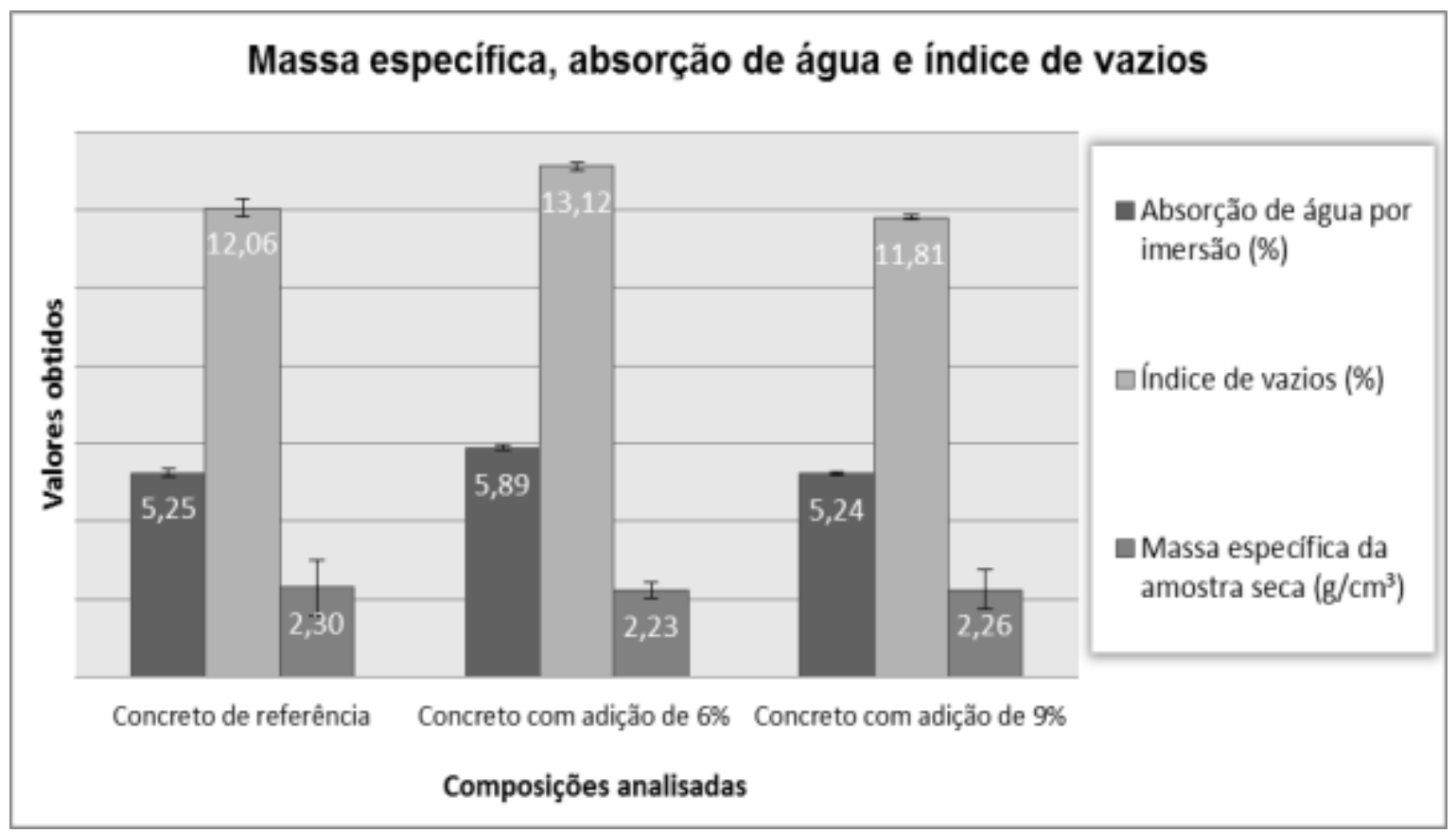

Figura 3: Massa Específica, Absorção de Água e Índice de Vazios.

A Tabela 3 apresenta os resultados individuais dos 3 corpos de prova utilizados para cada traço, a média aritmética dos valores obtidos, o desvio padrão, e as porcentagens de variação em cada um dos fatores analisados. Observa-se que o desvio padrão é muito pequeno, sendo que, para as amostras estudadas não houve grande dispersão nos resultados.

Era esperado que o concreto com maior adição de borracha apresentasse menor massa especifica. No entanto, devido ao traço com teor de $9 \%$ ter apresentado uma menor quantidade de poros, e consequentemente menor teor de ar incorporado, isso não ocorreu. Mesmo assim, os resultados obtidos são satisfatórios, demonstrando que a adição de borracha proporciona maior leveza ao concreto sem aumentar de forma significativa a sua absorção. 
Tabela 3: Resultados de Absorção de água, Índice de Vazios e Massa Específica.

\begin{tabular}{|c|c|c|c|}
\hline \multicolumn{4}{|c|}{ Absorção de água por imersão (\%) } \\
\hline & Referência & $6 \%$ de Adição & $9 \%$ de Adição \\
\hline Média aritmética & $5,25 \%$ & $5,89 \%$ & $5,24 \%$ \\
\hline Desvio Padrão & 0,11 & 0,05 & 0,03 \\
\hline Variação & - & $+10,86 \%$ & $-0,19 \%$ \\
\hline \multicolumn{4}{|l|}{ Índice de vazios (\%) } \\
\hline Média aritmética & $12,06 \%$ & $13,12 \%$ & $11,81 \%$ \\
\hline Desvio padrão & 0,22 & 0,10 & 0,06 \\
\hline Coeficiente de variação & - & $+8,08$ & $-2,07$ \\
\hline \multicolumn{4}{|c|}{ Massa específica da amostra seca $\left(\mathrm{g} / \mathrm{cm}^{3}\right)$} \\
\hline Média aritmética & 2,30 & 2,23 & 2,26 \\
\hline Desvio padrão & 0,72 & 0,21 & 0,50 \\
\hline Coeficiente de variação & - & $-3,04 \%$ & $-1,74 \%$ \\
\hline
\end{tabular}

\subsection{Análise da Morfologia da Superfície de Fratura}

Devido ao resíduo de borracha utilizado nesta pesquisa possuir uma distribuição de tamanhos e formas bem heterogênea, primeiramente foi feita a verificação da macroestrutura das amostras com o auxílio de um Estereoscópio Eletrônico. Dessa forma, foi possível observar as formas de arrancamento das fibras do concreto, bem como a adesão da borracha à pasta cimentícia. A Figura 4 apresenta as formas de aderência entre a matriz cimentícia e as fibras de borracha no compósito com teor de $6 \%$.
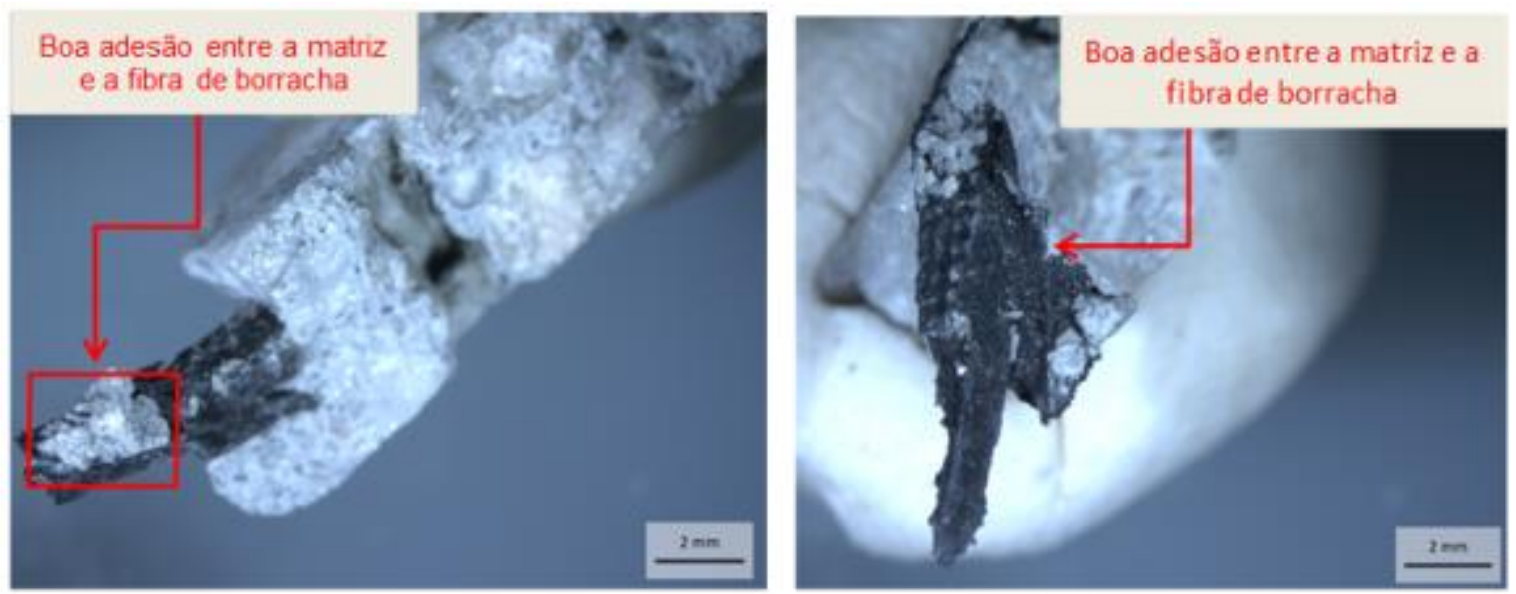

Figura 4: Análise Macroscópica das Amostras com Adição de 6\% de Borracha - Aumento de 6.3x

Nota-se que houve algumas áreas com boa aderência entre a pasta de cimento e a fibra de borracha, para o traço com $6 \%$ de adição, que foi a composição que apresentou a menor diminuição de resistência à compressão axial, sendo que o arranchamento, em sua maior parte, ocorreu por rompimento da fibra e não por Pull-out. Isso indica que apesar de haver uma fraca aderência entre a matriz cimentícia e a fibra de borracha no aspecto geral da estrutura, em determinados pontos houve uma aderência considerável devido às paredes rugosas da borracha. Tendo em vista que não foi utilizado nenhum tipo de tratamento prévio nas fibras, e que por isso a aderência ocorreu apenas em decorrência da estrutura morfológica da borracha, sendo, portanto, somente de natureza mecânica, os resultados se mostram satisfatórios. 
A Figura 5 apresenta as imagens do MEV no concreto com adição de $9 \%$ de borracha, com ampliação de 200x (a) e 50x em (b). Nesta imagem é possível observar a interface entre a fibra de borracha e matriz cimentícia. Também se verifica que o compósito com inserção de $9 \%$ de borracha apresenta algumas microfissuras, bem como microporos; estes dois fatores contribuem para explicar a queda nas propriedades mecânicas deste tipo de concreto, tendo em vista que a maior porosidade do material possibilitou a diminuição de sua resistência. No entanto, é valido salientar que estas foram análises pontuais do concreto, ou seja, esses fatores foram encontrados em apenas alguns pontos da estrutura, sendo que em outras partes, como as mostradas nas amostras macroscópicas, houve uma boa aderência entre a fibra a matriz cimentícia. Isto ajuda a explicar a reduzida queda nas propriedades mecânicas desse compósito quando comparados a outros estudos sobre o mesmo tema.
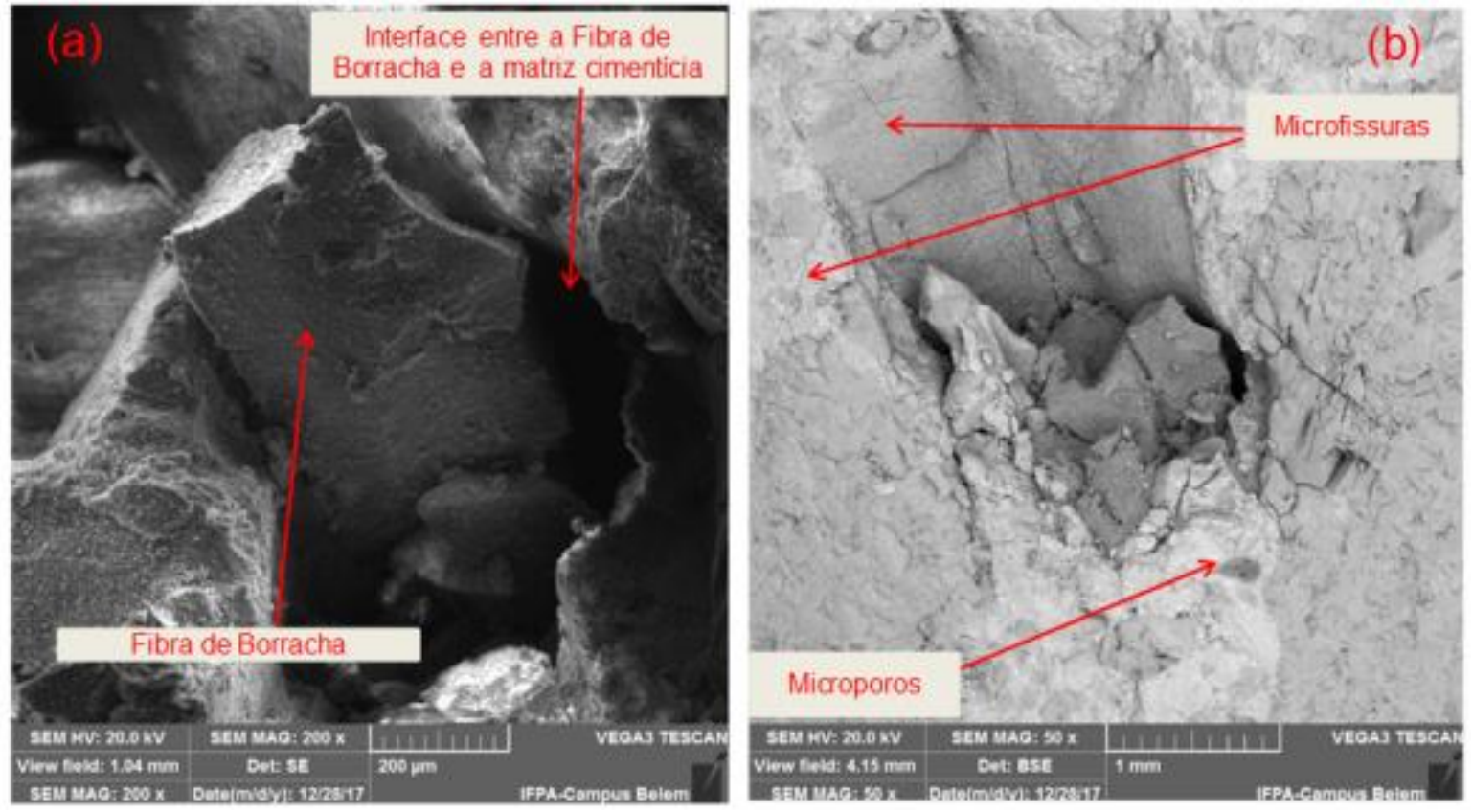

Figura 5: MEV da Fratura do Compósito com 6\% de Adição

\subsection{Análise Quantitativa do Benefício Ambiental Gerado Pelo Uso de Resíduos de Borracha de Pneus em Concreto}

A Tabela 4 apresenta os valores encontrados para a avaliação do benefício ambiental decorrente da inserção de resíduos de pneus para fabricação de concreto. Observa-se que, para a produção de $1 \mathrm{~m}^{3}$ de concreto com adição de $6 \%$ de borracha, o reaproveitamento de resíduos equivaleria a 26 processos de recauchutagem de pneu de caminhão e ônibus, 78 para os pneus de automóveis de passeio, e 156 para os de moto. Já para o compósito com teor de $9 \%$ de adição esse valor subiria para 39 processos de recauchutagem de pneu de caminhão e ônibus, 117 para os pneus de automóveis de passeio e 233 para os de moto. 
Tabela 4: Análise quantitativa do benefício ambiental do uso dos resíduos de pneus de recauchutagem

\begin{tabular}{|c|c|c|c|c|c|}
\hline \multirow[t]{2}{*}{ Tipo de Pneu } & \multirow{2}{*}{$\begin{array}{l}\text { Quantidade de } \\
\text { resíduos gerados no } \\
\text { processo de } \\
\text { recauchutagem }(\mathrm{kg})\end{array}$} & \multirow{2}{*}{$\begin{array}{l}\text { Quantidade de } \\
\text { borracha utilizada } \\
\text { para produção de } 1 \\
\mathrm{~m}^{3} \text { de concreto com } \\
\text { adição de } 6 \%(\mathrm{~kg})\end{array}$} & \multirow{2}{*}{$\begin{array}{c}\text { Quantidade de } \\
\text { borracha utilizada } \\
\text { para produção de } 1 \mathrm{~m}^{3} \\
\text { de concreto com } \\
\text { adição de } 9 \%(\mathrm{~kg})\end{array}$} & \multicolumn{2}{|c|}{$\begin{array}{c}\mathrm{N}^{0} \text { de processos de } \\
\text { recauchutagem realizados } \\
\text { para confecção de } 1 \mathrm{~m}^{3} \text { de } \\
\text { concreto (unidades) }\end{array}$} \\
\hline & & & & $6 \%$ & $9 \%$ \\
\hline $\begin{array}{c}\text { Caminhão e } \\
\text { ônibus }\end{array}$ & 1,2 & & & 26 & 39 \\
\hline $\begin{array}{c}\text { Automóveis de } \\
\text { passeio }\end{array}$ & 0,4 & 31,1 & 46,65 & 78 & 117 \\
\hline Moto & 0,2 & & & 156 & 233 \\
\hline
\end{tabular}

Estes resultados permitem verificar que utilização de resíduos de borracha de recauchutagem de pneu contribuiria de forma significativa para a diminuição dos danos causados pela disposição inadequada dos pneumáticos na natureza.

\subsection{Análise de Custos}

$\mathrm{Na}$ Tabela 5 é possível observar o comparativo de preços para produção de $1 \mathrm{~m}^{3}$ de concreto convencional, e para os concretos com adição de $6 \%$ e $9 \%$ de resíduo de borracha. Verifica-se que a adição da borracha, por possibilitar um maior incremento no volume do concreto, aumenta o seu rendimento promovendo uma redução nos valores de confecção deste compósito. O melhor resultado foi referente ao concreto com teor de $9 \%$ de adição que apresentou uma redução de custos da ordem de 4,17\% em relação ao concreto tradicional.

Tabela 5: Avaliação de Custos

\begin{tabular}{|c|c|c|c|c|c|c|c|}
\hline & \multicolumn{3}{|c|}{ Quantidades de Insumos } & \multirow{2}{*}{$\begin{array}{l}\text { Valor dos } \\
\text { Insumos }\end{array}$} & \multicolumn{3}{|c|}{ Valor para produção de $1 \mathrm{~m}^{3}$ de Concreto } \\
\hline & Ref. & $6 \%$ & $9 \%$ & & Ref. & $6 \%$ & $9 \%$ \\
\hline Cimento $(\mathrm{Kg})$ & 444,4 & 431,1 & 426,7 & $\mathrm{R} \$ 0,53$ & $\mathrm{R} \$ 235,55$ & $\mathrm{R} \$ 228,49$ & $\mathrm{R} \$ 226,13$ \\
\hline Seixo $\left(m^{3}\right)$ & 0,5 & 0,4 & 0,4 & $\mathrm{R} \$ 59,10$ & $\mathrm{R} \$ 27,13$ & $\mathrm{R} \$ 26,32$ & $\mathrm{R} \$ 26,05$ \\
\hline Areia $\left(\mathrm{m}^{3}\right)$ & 0,2 & 0,2 & 0,2 & $\mathrm{R} \$ 45,00$ & $\mathrm{R} \$ 8,88$ & $\mathrm{R} \$ 8.61$ & $\mathrm{R} \$ 8.52$ \\
\hline \multirow[t]{3}{*}{ Borracha $(\mathrm{Kg})$} & 0,0 & 31,1 & 46,65 & $\mathrm{R} \$ 0,00$ & $\mathrm{R} \$ 0,00$ & $\mathrm{R} \$ 0,00$ & $\mathrm{R} \$ 0,00$ \\
\hline & & & & Total & $\mathbf{R} \$ \mathbf{2 7 1 , 5 6}$ & $R \$ 263,42$ & $\mathbf{R} \$ 260,70$ \\
\hline & \multicolumn{4}{|c|}{ Redução de Custos (\%) } & - & $-3 \%$ & $-4 \%$ \\
\hline
\end{tabular}

Resultados semelhantes foram obtidos por GOMES FILHO [27] que indicou uma redução de até 7,6\% no custo do concreto com borracha se comparado com o concreto convencional, demonstrando a sua viabilidade comercial. Além disso, o concreto com borracha apresentou outras vantagens, tais como a redução do peso, o que facilita a manipulação e diminui o desgaste de equipamentos.

\section{CONCLUSÃO}


Este trabalho buscou avaliar a viabilidade técnica do uso de resíduos de recauchutagem de pneus para fabricação de concreto empregado em vias de pavimentação de baixo tráfego. Por meio dos ensaios realizados verificou-se a influência das porcentagens de resíduos inseridas nas propriedades mecânicas do concreto.

Para os traços analisados, a resistência à compressão axial simples foi reduzida em relação ao concreto de referência em 15,14\% para o compósito com adição 6\% de borracha e 17, 27\% para o traço com adição de $9 \%$. Isto pode ser devido à baixa aderência presente em alguns pontos entre a fibra de borracha e a matriz cimentícia. No entanto, esta redução pode ser considerada pequena levando-se em consideração as literaturas pesquisadas sobre o tema. Ressalte-se, ainda, que todos os três tipos de concreto analisados obtiveram resistências à compressão axial superiores ao que está previsto na ABNT: NBR 9781 [18], sendo, portanto, indicados para aplicação de pavimento intertravado de baixo tráfego.

No estado fresco foi observado que a trabalhabilidade dos concretos com adição de borracha foi reduzida em relação ao de referência. Para o compósito com adição de $6 \%$ a redução observada foi de $27.27 \%$ e para a composição com adição de $9 \%$ o valor obtido foi de $36,36 \%$. Todavia, não foi necessária alteração na relação água/cimento nem a utilização de aditivos, o que poderia encarecer o concreto produzido.

Todos os três traços de concreto analisados mostraram-se dentro dos parâmetros estabelecidos pela ABNT: NBR 9781 [18], a qual afirma que para concretos aplicados em pavimentação de baixo tráfego a absorção não pode ultrapassar o valor de $6 \%$. O compósito com adição de $9 \%$ apresentou um resultado mais satisfatório que o concreto tradicional, possuindo um menor teor de absorção da ordem de $0,19 \%$. Isto pode estar relacionado também ao processo de adensamento manual empregado nos corpos de prova.

Com relação à massa específica, a porcentagem de adição de borracha influencia diretamente a redução desta grandeza. $\mathrm{O}$ traço com $6 \%$ de adição mostrou-se o mais leve entre os três, tendo uma redução de 3,04\% de massa especifica em relação ao concreto convencional, sendo que o compósito com adição de $9 \%$ reduziu 1,74\%. Essa é uma característica importante para fabricação de concretos com peso reduzido, o que possibilitaria maior facilidade no transporte e aplicação de um pavimento.

Ao comparar os resultados obtidos, identifica-se que o teor ótimo de adição de resíduo é o de $9 \%$, pois apresenta uma redução na resistência à compressão axial de apenas $2,13 \%$ em relação ao teor de $6 \%$, sendo que se consegue incorporar uma maior quantidade de resíduo, contribuindo para a logística reversa deste material.

Através da análise quantitativa realizada neste trabalho, constatou-se que o uso de resíduos de borracha de pneus de recauchutagem em concreto é uma pratica altamente benéfica à gestão ambiental dos pneumáticos, que contribui de forma significativa para redução desse passivo ambiental.

Também se verificou que o concreto com borracha se torna economicamente viável por apresentar uma redução de custos de fabricação em relação ao concreto tradicional devido ao seu maior rendimento dado pelo grande volume do resíduo incorporado à mistura. O Traço com adição $6 \%$ de borracha apresenta um custo de produção menor de $3 \%$ em relação ao concreto convencional, enquanto que a composição com adição de $9 \%$ reduziu o custo em $4 \%$.

Conclui-se dessa forma que, do ponto de vista técnico, econômico e ambiental, o compósito produzido com inserção de borracha nos teores de $6 \%$ e $9 \%$ se mostra viável para produção de concreto empregado em pavimentação de baixo tráfego.

\section{BIBLIOGRAFIA}

[1] PELISSER, F., BERNADIN, A. M., "Concrete made with recycled tire rubber: Effect of alkaline activation and silica fume addition", Journal of Cleaner Production, v. 8, n. 2361, pp. 1-7, Dezembro de 2010.

[2] ANIP - ASSOCIAÇÃO NACIONAL DE INDÚSTRIAS DE PNEUMÁTICOS, www.anip.com.br. Acessado em outubro de 2017.

[3] RESOLUÇÃO DO CONAMA $\mathrm{n}^{\mathrm{o}} 258$ de 26 de Agosto de 1999, http://www.mma.gov.br/port/conama/res/res99/res25899.html. Acessado em outubro de 2017.

[4] REVISTA PESQUISA FAPESP, ed., 246, revistapesquisa.fapesp.br/2016/08/19/reciclagem-de-pneus/. Acessado em agosto de 2016.

[5] BERTOLLO, S. A. M. et al., "Pavimentação Asfáltica: uma alterativa para reutilização de pneus usados", Revista Limpeza Pública, ed. 54, pp. 23-30, Janeiro de 2000. 
[6] OLIVEIRA, O. J., CASTRO, R.de., "Estudo da destinação e da reciclagem de pneus inservíveis no Brasil”, In: XXVII Encontro Nacional de Engenharia de Produção, 239-57, Foz do Iguaçu, PR, Brasil, 09 a 11 de outubro de 2007.

[7] GRANZOTTO, L., Concreto com adições de borracha: uma alternativa ecologicamente viável. Tese de M. Sc., UEM, Maringá, PR, Brasil, 2010.

[8] FIORITI, C. F. et al., “Avaliação de blocos de concreto para pavimentação intertravada com adição de resíduos de borracha provenientes da recauchutagem de pneus”, ambiente Construído, v. 7, n. 4, pp. 43-54, outubro de 2007.

[9] LINTZ, R. C. C., GACHET-BARBOSA, L. A., Avaliação do comportamento de concreto contendo borracha de pneus inservíveis para utilização em pisos intertravados. Tese de M. Sc., UNICAMP, Limeira, SP, Brasil, 2010.

[10] SILVA, JR. F. A., Avaliação do efeito da adição de resíduo de borracha de pneu e brita calcária na formulação de compósitos cimentíceos. Tese de D. Sc., UFRN, Natal, RN, Brasil, 2014.

[11] ALTOÉ, S. P. S., “Avaliação da resistência mecânica de pavers fabricados com resíduos de pneus em substituição parcial do agregado miúdo”, Synergismus scyentifica UTFPR, v. 12, n. 1, pp. 262-268, novembro de 2017.

[12] KROTH, L. A., Análise mecânica e química de placas pré-moldadas de concreto com adição de resíduo de borracha de pneus. Tese de M. Sc., UFSM, Santa Maria, RS, Brasil, 2012.

[13] ASSOCIAÇÃO BRASILEIRA DE NORMAS TÉCNICAS. NBR 248 - Agregados - Determinação da composição granulométrica, Rio de Janeiro, 2003.

[14] ASSOCIAÇÃO BRASILEIRA DE NORMAS TÉCNICAS. NBR NM 52 - Agregado miúdo Determinação de massa específica, massa específica aparente, Rio de Janeiro, 2009.

[15] ASSOCIAÇÃO BRASILEIRA DE NORMAS TÉCNICAS. NBR NM 53 - Agregado graúdo Determinação de massa específica, massa específica aparente e absorção de água, Rio de Janeiro, 2009.

[16] AMERICAN SOCIETY FOR TESTING AND MATERIALS. ASTM C 792 - Standard Test Methods for Density and Specific Gravity (Relative Density) of Plastics by Displacement, Philadelphia, 2015.

[17] ASSOCIAÇÃO BRASILEIRA DE NORMAS TÉCNICAS. NBR NM 45 - Agregados - Determinação da massa unitária e do volume de vazios, Rio de Janeiro, 2006.

[18] ASSOCIAÇÃO BRASILEIRA DE NORMAS TÉCNICAS. NBR 9781 - Peças de concreto para pavimentação - Especificação e método de ensaio, Rio de Janeiro, 2013.

[19] ASSOCIAÇÃO BRASILEIRA DE NORMAS TÉCNICAS. NBR NM 67 - Concreto - Determinação da consistência pelo abatimento do tronco de cone, Rio de Janeiro, 1998.

[20] ASSOCIAÇÃO BRASILEIRA DE NORMAS TÉCNICAS. NBR 5739 - Concreto - Ensaio de compressão de corpo de prova cilíndrico, Rio de Janeiro, 2007.

[21] ASSOCIAÇÃO BRASILEIRA DE NORMAS TÉCNICAS. NBR 5738 - Procedimento para Moldagem e Cura dos Corpos de Prova, Rio de Janeiro, 2015.

[22] ASSOCIAÇÃO BRASILEIRA DE NORMAS TÉCNICAS. NBR 9778 - Argamassa e concreto endurecido - determinação da absorção de água, índice de vazios e massa específica, Rio de Janeiro, 2009.

[23] ASSOCIAÇÃO BRASILEIRA DE NORMAS TÉCNICAS. NBR 7211-Agregados para Concreto. Rio de Janeiro, 2009.

[24] ROMUALDO, A. C. A., et al., "Pneus Inservíveis como Agregados na Composição de Concreto para Calçadas de Borracha", In: $3^{\text {rd }}$ International Workshop Advances in Cleaner Production - Cleaner Production Initiatives and Challenges for a Sustainable World, pp. 18-20, São Paulo, maio de 2011.

[25] BRITO, G. P. S., Estudo da Viabilidade Técnica de Paver com Resíduo de Pneu em Substituição Parcial dos Agregados. Tese de M. Sc., UNIPAMPA, Alegrete, RS, Brasil, 2013.

[26] MOREIRA, J. F., et al., "Concreto com borracha de pneus aplicado em ciclovia", HOLOS Environmental, v. 14, n. 2, pp. 185-197, setembro de 2014.

[27] GOMES F. C. V., Levantamento do Potencial de Resíduos de Borracha no Brasil e Avaliação de Sua Utilização na Indústria da Construção Civil. Tese de M. Sc., IEP, Curitiba, PR, Brasil, 2007. 


\section{ORCID}

Luzilene Silva

https://orcid.org/0000-0002-5424-2561

Laércio Gomes

https://orcid.org/0000-0002-8474-0748

Marília Barata

https://orcid.org/0000-0003-2612-6747

Ribamar Mouta

https://orcid.org/0000-0002-7443-3912 